\title{
A Simple Framework for the Cost-Benefit Analysis of Single-Task Construction Robots Based on a Case Study of a Cable-Driven Facade Installation Robot
}

\author{
Rongbo Hu ${ }^{1, *(D)}$, Kepa Iturralde ${ }^{1}$, Thomas Linner ${ }^{1}$, Charlie Zhao ${ }^{1}$, Wen Pan ${ }^{1}$, Alessandro Pracucci ${ }^{2}$ and \\ Thomas Bock ${ }^{1}$ (D) \\ 1 Chair of Building Realization and Robotics, Department of Architecture, Technical University of Munich, \\ 8033 Munich, Germany; kepa.iturralde@br2.ar.tum.de (K.I.); thomas.linner@br2.ar.tum.de (T.L.); \\ charlie.zhao@br2.ar.tum.de (C.Z.); wen.pan@br2.ar.tum.de (W.P.); thomas.bock@br2.ar.tum.de (T.B.) \\ 2 Innovation Department, Focchi S.p.A., 47824 Poggio Torriana, Italy; a.pracucci@focchi.it \\ * Correspondence: rongbo.hu@br2.ar.tum.de
}

Citation: Hu, R.; Iturralde, K.; Linner, T.; Zhao, C.; Pan, W.; Pracucci, A.; Bock, T. A Simple Framework for the Cost-Benefit Analysis of Single-Task Construction Robots Based on a Case Study of a Cable-Driven Facade Installation Robot. Buildings 2021, 11, 8. https://dx.doi.org/10.3390/ buildings11010008

\section{Received: 1 December 2020}

Accepted: 21 December 2020

Published: 24 December 2020

Publisher's Note: MDPI stays neutral with regard to jurisdictional claims in published maps and institutional affiliations.

Copyright: (c) 2020 by the authors. Licensee MDPI, Basel, Switzerland. This article is an open access article distributed under the terms and conditions of the Creative Commons Attribution (CC BY) license (https: / creativecommons.org/ licenses/by/4.0/).

\begin{abstract}
Single-task construction robots (STCRs) have become a popular research topic for decades. However, there is still a gap in the ubiquitous application of STCRs for onsite construction due to various reasons, such as cost concerns. Therefore, cost-benefit analysis (CBA) can be used to measure the net economic benefit of the STCRs, compared to traditional construction methods, in order to boost the implementation of STCRs. This paper presents a simple and practical framework for the economic evaluation of STCRs and conducts a case study of a cable-driven facade installation robot to verify the method. The results show that the cable-driven robot for facade installation is worth investing in in the UK, as well as in the majority of G20 countries. Furthermore, other socioenvironmental implications of STCRs and the limitations of the study are also discussed. In conclusion, the proposed method is highly adaptable and reproducible. Therefore, researchers, engineers, investors, and policy makers can easily follow and customize this method to assess the economic advantages of any STCR systems, compared to traditional construction technologies.
\end{abstract}

Keywords: cable-driven parallel robot; construction robot; cost-benefit analysis; curtain wall modules; economic evaluation; facade installation

\section{Introduction}

Ever since the first debut in the 1970s in Japan, single-task construction robots (STCRs) have become a worldwide research and development topic. They are robots or automated devices that are developed primarily for tasks on the construction sites [1]. It is a highly cross-disciplinary field which requires an integration of a variety of knowledge and expertise such as civil engineering, architecture, industrial design, construction management, robotics, mechanical engineering, electrical engineering, and informatics. Today, the application fields of STCRs continue to expand. For instance, Bock and Linner summarized 200 existing STCR systems into 24 categories based on their functions [2]. However, currently, there is still a gap in the ubiquitous application of STCRs for onsite construction due to various reasons, such as insufficient proof of net economic benefits, lack of modularity in building components, lack of skilled labor for operation, incompatibility with other construction tasks, and time-consuming onsite setup [2]. Therefore, more research evidence is needed to prove the net economic benefit of the STCRs, compared to traditional construction methods, in order to boost the speed and breadth of the implementation of STCRs. Cost-benefit analysis (CBA) is oftentimes considered as one of the most important problem-solving tools in decision-making processes, yet there is a lack of research on the quantitative evaluation of STCR systems to study their economic implications for key stakeholders. This paper aims to propose a simple methodological framework for the 
cost-benefit analysis of STCRs based on the case study of the onsite cable-driven facade installation robot developed in the EU research project named Hephaestus.

Cost-benefit analysis (CBA) is commonly used for economic evaluation of a project or policy. It can be dated back to the mid-19th century by French engineer and economist Jules Dupuit [3]. It is a policy assessment tool that monetizes all impacts of a project or policy to all relevant stakeholders in society [4]. According to Munger, CBA is considered as the "single most important problem-solving tool in policy work" [5]. The CBA usually can be divided into several major steps in order to make the process more manageable. The steps can usually be described as follows [4].

- Specify the set of alternatives projects.

- Decide who will be the key stakeholder for the benefits and costs.

- List impacts and determine ways to measure them.

- Predict impacts quantitatively over the life of the project.

- Monetize every impact.

- Discount benefits and costs to obtain present values.

- Calculate the net present value of each alternative.

- Perform sensitivity analysis.

- Make a recommendation.

Like every assessment tool, CBA has certain limitations, such as its imperfect process, its monetization of non-market articles, the openness of the results, the thorough examination by the public, its dependence on correctness and completeness, the difficulty of being understood, its ethics, and its neglect of long-term environmental impacts [4]. Nevertheless, considering its wide usage in the policy-making activities, it is naturally reasonable to apply CBA as a tool to evaluate the economic benefits of STCR systems.

\section{Literature Review}

With regard to the construction industry, there have been several instances of CBA research available to the public. In particular, Shen et al. compared the costs and benefits of prefabricated public housing projects and traditional housing projects based on survey and field research [6]. The research reported an analysis of construction costs and environmental benefits of prefabricated housing, largely based on collected questionnaires from more than 50 managers, which takes a great amount of efforts. Li and Mandanu proposed an uncertainty-based methodology for the life-cycle CBA of highway projects that handles certainty, risk, and uncertainty [7], which requires accessing a large amount of historical data. In addition, Medici and Lorenzini proposed a mathematical model for optimizing energy-saving measures on the building envelope, which reveals the relationship between energy benefit and the related cost [8]. With regard to construction automation, Jang and Skibniewski conducted a CBA of an embedded sensing system for construction material tracking, compared to manual materials tracking, method based on interviewing the experts regarding labor productivity [9]. Another interesting research by García de Soto et al. compared the productivity of robot fabrication to that of manual technique in building complex concrete walls [10], but, strictly speaking, it is a cost and time analysis rather than a comprehensive CBA. Furthermore, Kim et al. developed an assessment tool to evaluate the economic efficiency of an integrated automated onsite construction system [11], focusing on assessing an integrated automated construction system rather than a specific STCR.

These precedents provide insightful knowledge of economic evaluation for the construction sector. However, few of these methods are specifically designed for conducting the CBA of STCR systems, due to the lack of accumulated information in practical applications of construction robots, even though the research field of STCR systems is becoming more popular in recent years.

Therefore, developing a practical method of CBA for evaluating STCR systems would be beneficial to both academia and industry. The goal of this research is to explore a simple framework for the cost-benefit analysis of STCRs, compared to conventional methods, which can be quickly adapted and used for evaluating other STCR systems. The framework 
will be verified in the case study of onsite facade installation performed by the cable-driven robot developed in the Hephaestus project. The results of the case study can help determine whether the Hephaestus robot is worth investing in for construction companies. More importantly, this framework can be easily adapted to evaluate other STCR systems in various contexts. Furthermore, the results can provide evidence for the policy makers to decide how many resources shall be allocated or invested to the research and development of automated construction technologies.

\section{Methods}

As mentioned above, this research aims at proposing a simplified method for performing the economic evaluation for construction robots. In this section, the analytical framework and cashflow analysis table for calculation are proposed in general, which, later, is applied to the case study thereafter.

\subsection{Analytical Framework for the CBA}

In order to compare the STCR solutions to the conventional construction methods, the following simple and practical analytical framework for CBA is proposed (see Figure 1). The CBA in this article will follow this analytical framework.

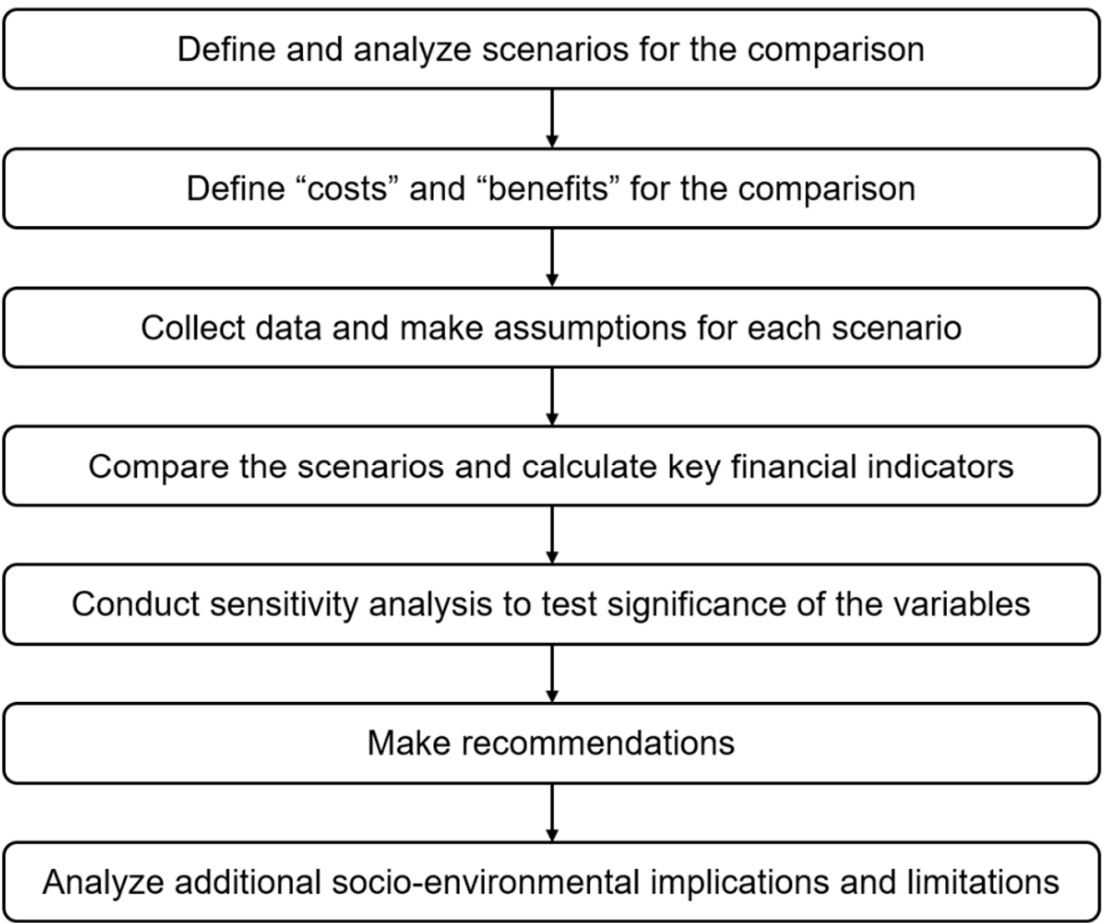

Figure 1. The analytical framework of cost-benefit analysis (CBA) applied in this research.

\subsection{Cashflow Analysis Table}

In the calculation process of the CBA, all relevant factors that affect the main stakeholder need to be considered. Normally, the cashflow analyses for CBA range from at least three (small-scale projects) to more than ten years (e.g., large-scale public projects) $[7,12,13]$. The five-year calculation period here is mainly because the engineering partners in the project estimate that the lifecycle of such types of construction robots will likely be approximately five years. More importantly, for individual companies as the key beneficiaries, the investment will not be attractive for them if the payback period is longer than five years (e.g., 10 years or above). Therefore, five years is a reasonable time horizon for economic evaluations of STCRs. As a result, a comparison table between conventional methods and STCR solutions is designed which takes every factor during the onsite construction task into consideration in a five-year period (see Figure 2). 


\begin{tabular}{|c|c|c|c|c|c|c|c|}
\hline \multicolumn{8}{|c|}{ Cashflow analysis to compare novel STCR solution and conventional method } \\
\hline Key stakeholder/beneficiary & & & & & & & Operating region \\
\hline Cash outflows & Year 1 & Year 2 & Year 3 & Year 4 & Year 5 & Total (€) & Explanation and remarks \\
\hline \multicolumn{8}{|l|}{ Central - hardware costs } \\
\hline \multicolumn{8}{|l|}{ Central - software costs } \\
\hline \multicolumn{8}{|l|}{ Central - network costs } \\
\hline \multicolumn{8}{|l|}{ Central - utility costs } \\
\hline \multicolumn{8}{|l|}{ Central - operation } \\
\hline \multicolumn{8}{|l|}{ Central- maintenance } \\
\hline \multicolumn{8}{|l|}{ Central - other } \\
\hline \multicolumn{8}{|l|}{ Per robot costs - hardware } \\
\hline \multicolumn{8}{|c|}{ Per robot costs - software } \\
\hline \multicolumn{8}{|c|}{ Per robot costs - network \& utility } \\
\hline \multicolumn{8}{|l|}{ Per robot costs - training } \\
\hline \multicolumn{8}{|l|}{ Per robot costs - transport } \\
\hline \multicolumn{8}{|l|}{ Per robot costs - installation } \\
\hline \multicolumn{8}{|l|}{ Per robot costs - operation } \\
\hline \multicolumn{8}{|l|}{ Per robot costs - disassembly } \\
\hline \multicolumn{8}{|l|}{ Per robot - maintenance } \\
\hline \multicolumn{8}{|l|}{ Per robot - other } \\
\hline \multicolumn{8}{|l|}{ Total outflow } \\
\hline \multicolumn{8}{|l|}{ Savings - equipment } \\
\hline \multicolumn{8}{|l|}{ Savings - labor } \\
\hline \multicolumn{8}{|l|}{ Savings - utility } \\
\hline \multicolumn{8}{|l|}{ Savings - operational } \\
\hline \multicolumn{8}{|l|}{ Savings - maintenance } \\
\hline \multicolumn{8}{|l|}{ Savings - other } \\
\hline \multicolumn{8}{|l|}{ Total savings } \\
\hline \multicolumn{8}{|l|}{ Net annual cashflow } \\
\hline \multicolumn{8}{|l|}{ Net cumulative cashflow } \\
\hline Coefficient of productivity & & & & & & & \\
\hline Annual wage increase & & & & & & & \\
\hline
\end{tabular}

Figure 2. Template of the cashflow analysis.

In this template, the light grey cells indicate the cost and saving aspects that need to be taken into consideration, whereas the white cells are used to input values for each cost and saving aspect in the respective year. Each line of item is followed by an "explanation and remarks" cell to describe the respective item in detail (e.g., explanation, calculation, additional information, etc.)

In particular, in the cash outflow category, the "central" rows indicate the indirect costs that a construction company needs to bear in their headquarters in order to run each robot system for a specific task each year, whereas "per robot costs" rows indicate the direct costs of each robot system each year. The "savings" rows indicate the costs of conventional construction method to conduct the same task each year. The "explanations and remarks" row can be used to explain how each row is calculated. If by, or before, year 5 the net cumulative cashflow turns from negative to positive, it suggests that the STCR system is likely to be worth investing in. Furthermore, based on the result of this table, key financial indicators can be calculated accordingly.

In the next section, a case study of an STCR project for facade installation is conducted, and a CBA of the STCR system is performed, based on the proposed framework, in order to verify the method.

\section{Case Study}

After the comparison framework is defined, a case study comparing the conventional curtain wall installation method and the alternative Hephaestus cable-robot solution is conducted, as follows.

\subsection{Curtain Wall Installation Process}

A curtain wall is an exterior envelope of the building that does not carry any vertical loads of the roof or floor. It supports its own weight as well as other imposed loads, such as wind, and transfers these forces to the building structure. It provides benefits such as daylight shading, insulation, and weight reduction [14]. Normally there are two types 
of curtain wall installations: (1) the stick system, where the assembly of the curtain wall components such as frames and glass panes, takes place on site; (2) the unitized modular system, where the prefabricated curtain wall modules (CWMs) are installed onsite. Due to the scope of this research, only the unitized prefabricated module system is considered. The standard CWM installation consists of four main steps, which are (1) bracket installation, (2) lifting the CWM, (3) CWM installation with position adjustment, and (4) CWM unit fixation (see Figure 3) [15].

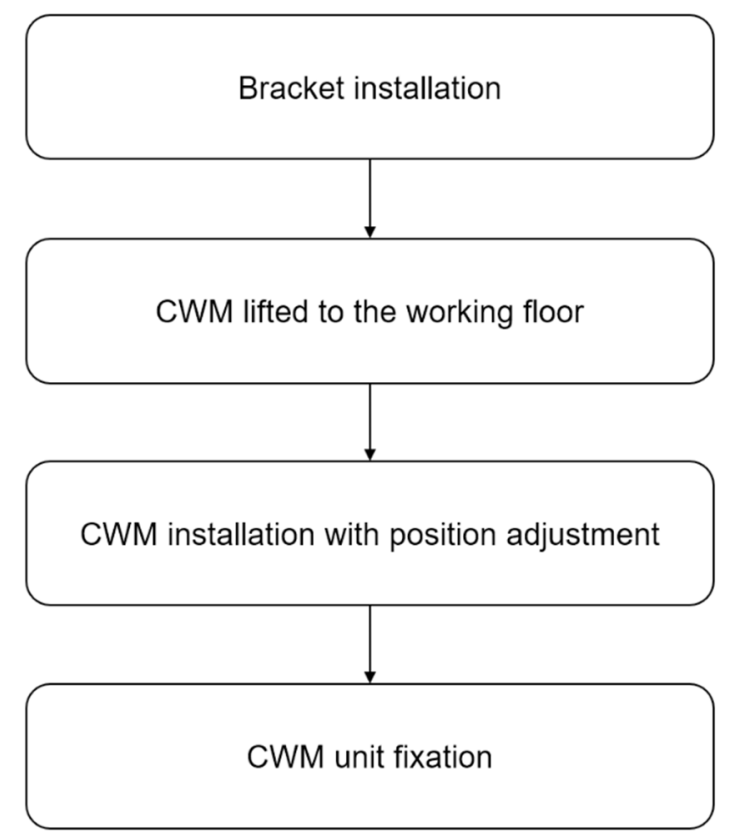

Figure 3. Four main steps in the curtain wall module (CWM) installation.

\subsection{Conventional CWM Installation}

In the first step of installation, the brackets will be manually installed to the building floors. There are two main techniques for bracket installation: the cast-in channel technique and the drilling technique. In the cast-in channel technique, the channels are welded onto the rebars of the framework before pouring the concrete, whereas the drilling technique requires drilling holes based on pre-measured drilling points which avoid rebars underneath. In the context of this research, only the drilling technique is involved. During the bracket installation process, the position of the CWM will be checked and controlled by using measurement systems such as a total station. The placement of the brackets is critical and will likely not be readjusted later. In the meantime, the modules will be transported to the construction site and stored after being unpacked and assembled. In the second step, the CWM will be lifted by the crane to the working floor (or, alternatively, in some cases, be elevated to the working floor through an elevator if possible). In the third step, while the crane holds the weight of the CWM, workers on the working floor minutely adjust the position of the CWM to ensure its installation to the brackets. Finally, after the position of the CWM is correctly confirmed, workers on the working floor fix the unit and the next CWM installation starts (see Figure 4) [15]. 


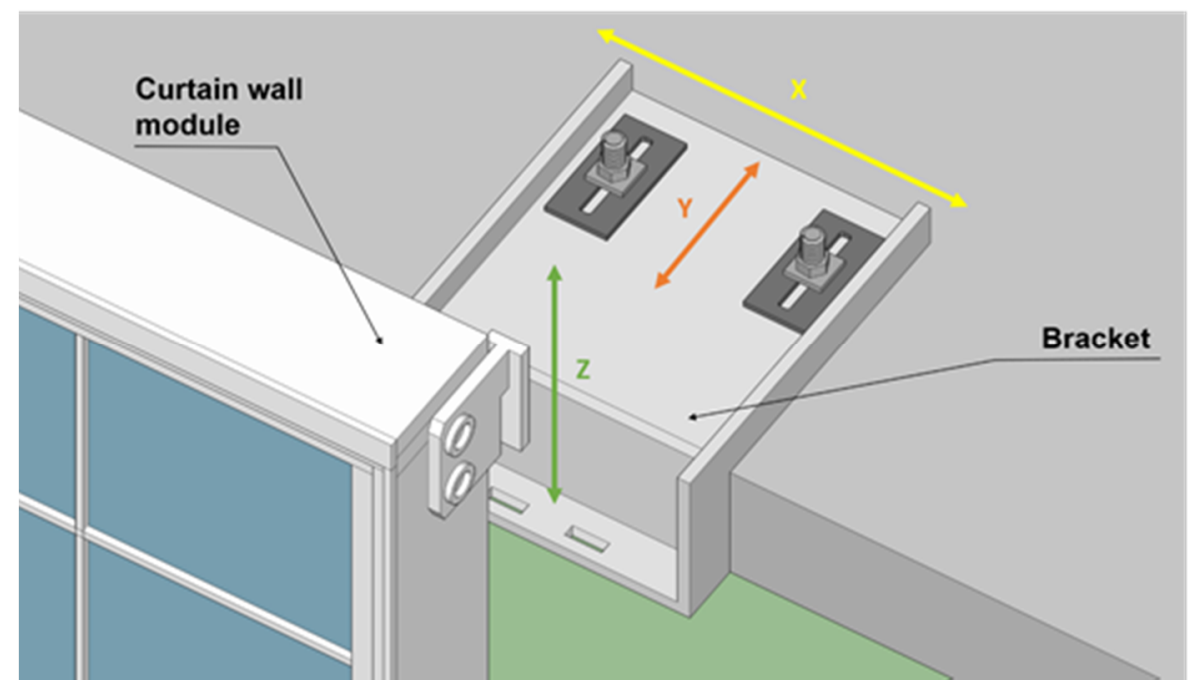

Figure 4. Schematic diagram of a typical bracket on the concrete building floor and its connection with a CWM module (the drilling technique).

Therefore, in the conventional CWM installation process, all the four steps are done manually by workers with the help of certain machines. The installation of brackets is completed by workers one by one manually, which is highly time-consuming. As demonstrated in Figure 5, the manual method normally involves several workers to work together at height, creating high labor costs and potential danger for these workers (e.g., injuries caused by machinery, back injuries from heavy lifting, falls from height, hearing loss from long-term exposure to loud machinery, etc.). In addition, workers on the ground, for component handling, and a tower crane, for CWM positioning, are necessary as well.

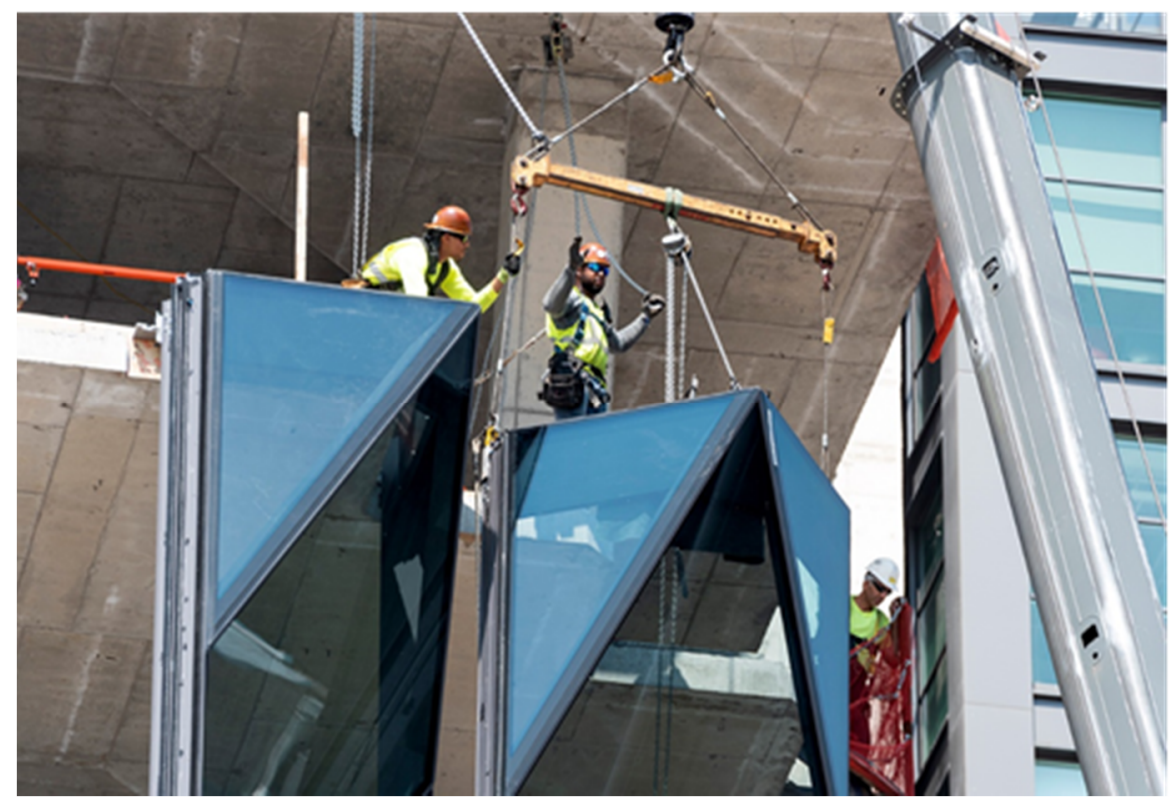

Figure 5. Several workers working at height during the CWM installation process (facade installation in Solar Carve Tower, New York. Facade engineered and manufactured by Focchi Group; photo by Timothy Schenck).

\subsection{Automated CWM Installation}

There are several existing instances of automated curtain wall installation. For example, a patented method developed by Brunkeberg Systems AB uses a dedicated railing system to automatically install specially-designed CWMs from the outside of a build- 
ing [16]. However, the railing installation process is manual, and might not apply to certain types of buildings. Other researchers reported a mobile robot that can perform facade installation from the inside of the building, but it only managed to automate the third step, which is positioning the CWM. Činkelj et al. developed a hydraulic telescopic system that installs facade panels to the building from the outside. However, this semi-automated, tele-operated system is specialized for handling facade panels rather than CWMs, and there is also a height limitation due to the use of a telescopic handler [17]. In addition, researchers also proposed other novel solutions for the automatic installation of the facade, but many are still at conceptual level [18-21].

Therefore, the Hephaestus cable-driven robot was primarily developed for the CWM installation task, although various functions can be achieved by reprogramming the robot and replacing the end-effector. It is arguably the first cable-driven parallel robot (CDPR) in the world that is designed, built, and deployed specifically for curtain wall installation.

The CWM installation, as explained above, consists of four main steps: bracket installation, panel lifting, position adjusting, and panel fixation, which are the main tasks of the Hephaestus robot. The advantages of the robot are the large range of workspace, high payloads, reconfigurability, and modularity, making the system easily transportable and highly adjustable to adapt to various situations.

In terms of geometry, a CDPR is a configuration of cables with variable lengths connecting a drawing point attached to the base frame, and a fixing point attached to the mobile platform. The geometrical design of the CDPR can be defined by the following parameters: (1) number of cables, (2) geometry of the structure, (3) geometry of the platform, and (4) cable configurations. Previous studies indicate that CDPR driven by eight cables will have appropriate performance, thus the number of cables was chosen [22]. The geometries of the structure and platform were determined by the positions of the drawing points and attachment points, respectively.

The Hephaestus CDPR consists of seven subassemblies. There are two drawing point assemblies on the top of the building, and four on the bottom, controlling the lengths of the cables (see Figure 6a). In the center is the working platform subassembly, featuring eight fixing points, as well as the power system and various tools for the modular end-effector. In the Hephaestus project, two major tasks need to be performed: (1) the fixation of the bracket onto the concrete slab, which is performed by the robotic arm (see Figure 7), and (2) the placement of the CWMs onto the brackets by a vacuum system attached to the bottom of the CDPR platform (see Figure 6b). In addition, a linear system with vacuum cups serving as a stabilizer is also integrated in the platform in order to stabilize the working platform subassembly (see Figure 8) [23].

In addition, the CDPR features a control room (i.e., a small movable container equipped with computers and other relevant devices) which serves as the "brain" of the system. Currently, the CDPR (prototype) does not directly integrate advanced digital construction technologies. The main tasks, such as bracket installation and CWM positioning, are preprogrammed based on traditional CAD drawings. However, since the CDPR is equipped with adequate hardware and software capabilities, it certainly has the potential to integrate digital construction technologies, such as building information modeling (BIM) and digital twin, in future iterations in order to enhance its speed and performance. 


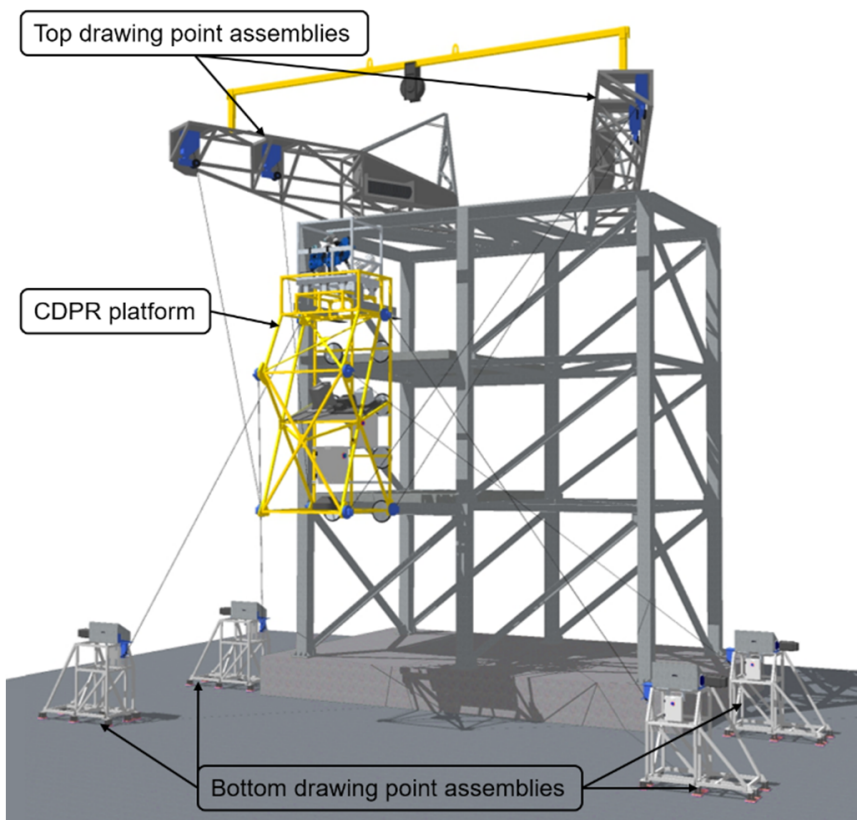

(a)

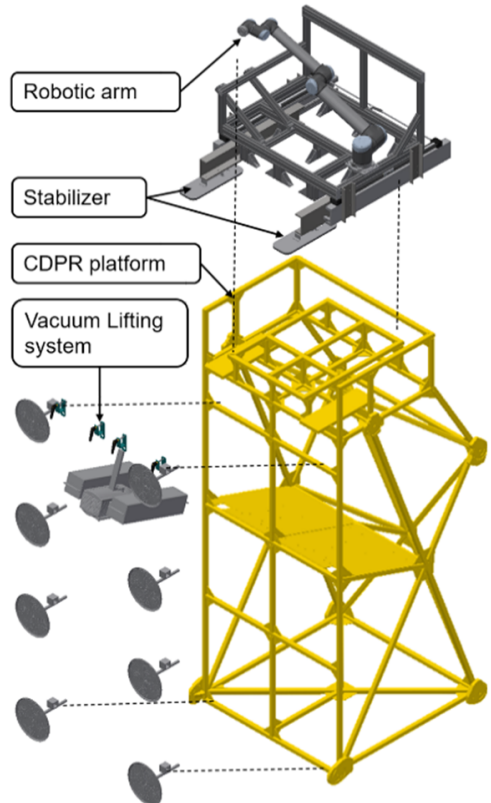

(b)

Figure 6. (a) Design of the Hephaestus cable-driven parallel robot (CDPR) prototype; (b) detailed depiction of the modular end-effector of the CDPR system.

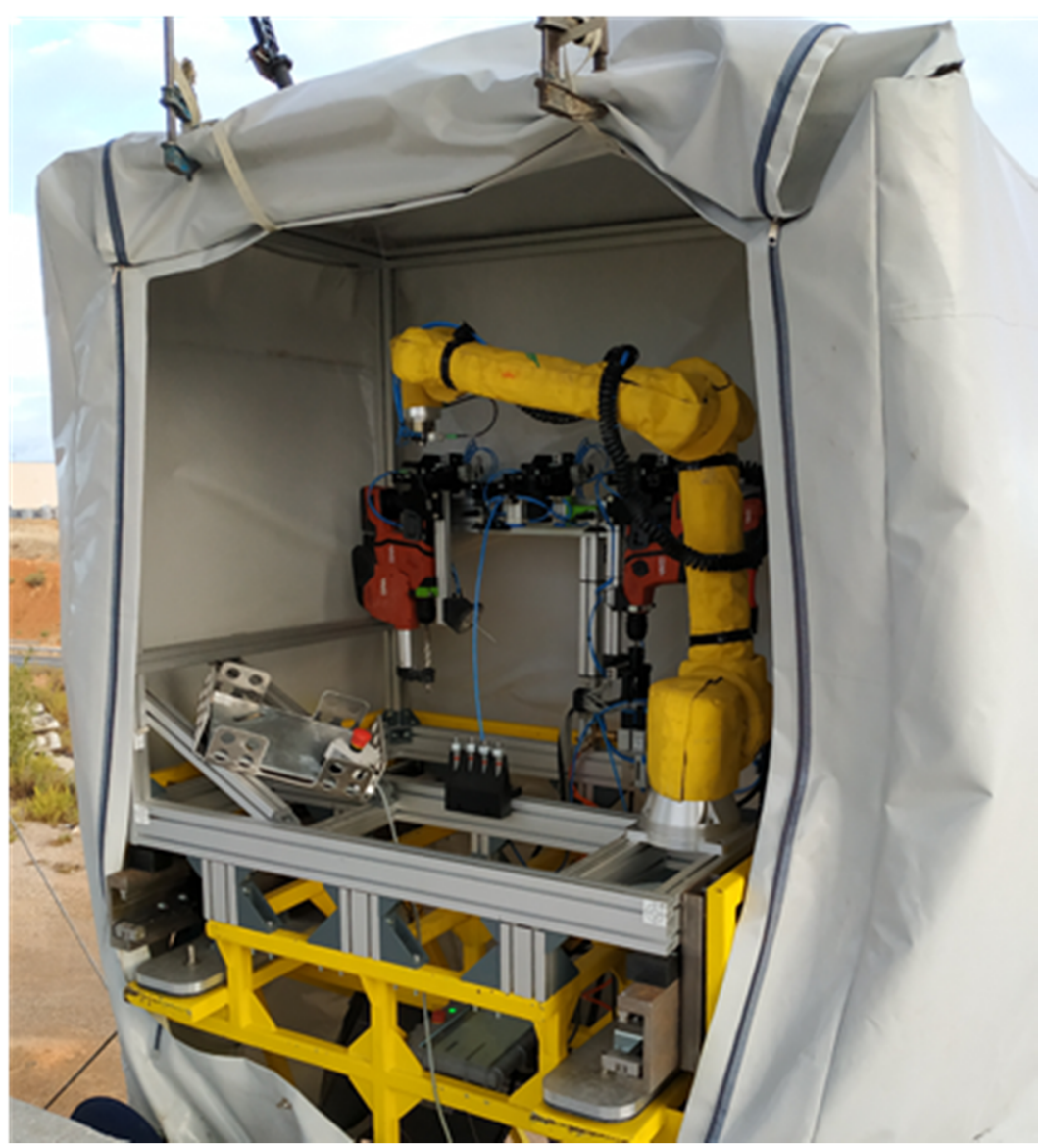

Figure 7. Robotic arm and its tools for bracket installation protected by weatherproof covers (photo: José David Jiménez-Vicaría). 


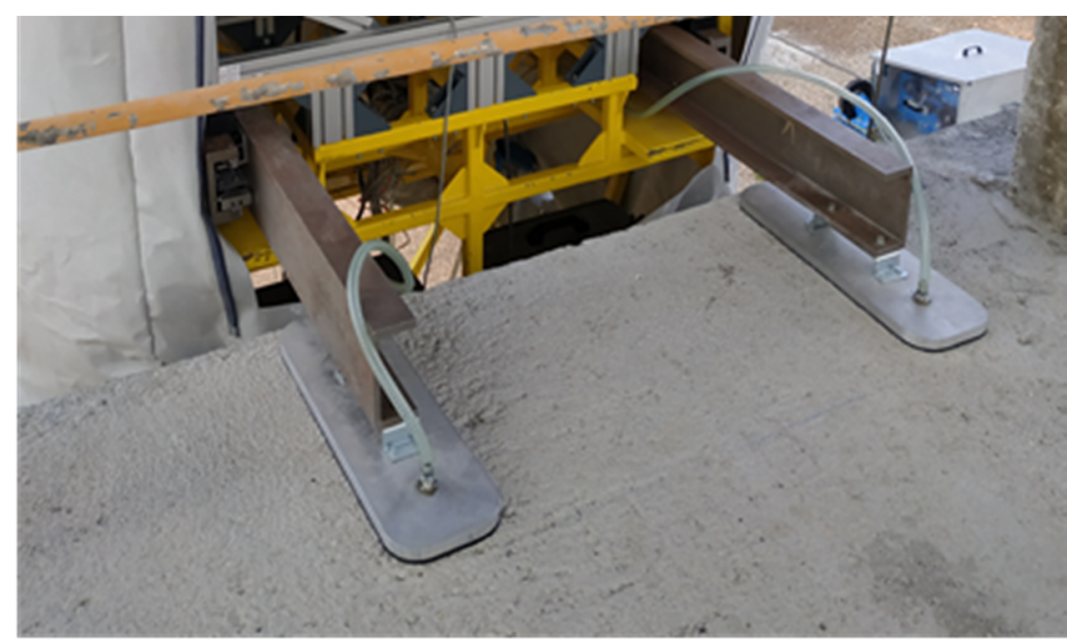

Figure 8. Stabilizer attaching the robot platform to the concrete slab (photo: José David Jiménez-Vicaría).

\subsection{Determining the Scenario for Evaluation}

Based on discussions and communications with partners of the Hephaestus project, a presumptive scenario for comparison can be proposed, as below (see Table 1). In this scenario, it is assumed that the facade installation company (i.e., Focchi Group UK) owns the robot during its lifecycle, because the company generated 133.90 million US dollars in revenue in 2019, which is large enough to fully employ more than one Hephaestus robot system.

In the case of curtain wall installation, the service charge is highly case-dependent (i.e., not only decided by the working area, but also by the form and shape of facade, type of CWM, etc.) and thus not easy to determine broadly. Usually, the representatives at the construction company carefully evaluate the building and requirements and provide an offer to the client thereafter. Therefore, a situation is assumed where the two scenarios execute exactly the same amount of workload (thus yielding the same revenue) based on the productivity of one robot system. In this way, many uncertainties can be avoided in determining the revenue that the company can make in the two scenarios. Similar to the concept of a controlled experiment in biology, in this research the variable "revenue" is controlled. Then, the costs of adopting the robot system and the benefits of saving money by avoiding the conventional method are compared. In other words, the costs here equal the money spent to operate the robot system, and the benefits equal the money saved by not using the conventional CWM installation method.

Table 1. Conventional and alternative scenarios defined for the comparison.

\begin{tabular}{ccc}
\hline Category & Scenario 1 & Scenario 2 \\
\hline Name & Hephaestus cable-driven robot & Conventional facade installation \\
\hline Key beneficiary & Facade installation company (Focchi Group UK) \\
\hline Business model & Owning the robot & Paid based on working area, etc. \\
\hline Primary location for calculation & & United Kingdom \\
\hline Investment period & 5 years (the assumed lifecycle of the robot according to the engineering partners in the project) \\
\hline Main equipment required & 1 cable-driven robot & 1 crane for positioning \\
\hline Estimated average area per job & $540 \mathrm{~m}^{2}(\mathrm{~L} 30 \mathrm{~m} \times \mathrm{H} 18 \mathrm{~m} ; 1.5 \mathrm{~m} \times 3$ m per panel)
\end{tabular}




\subsection{Gathering Data and Proposing Assumptions for Calculating the Costs of the Conventional and} Alternative Scenarios

The data needed for the calculation in the cashflow analysis table are collected by various means such as market research, online meetings, calls, and emails with key stakeholders (e.g., the facade installation partner, the robot developing partner). Based on the data-gathering activities, the following information, which is crucial to the calculation, is demonstrated in Table 2.

Table 2. Data collected for the cashflow analysis of the two scenarios.

\begin{tabular}{|c|c|c|}
\hline Category & Scenario 1 & Scenario 2 \\
\hline Name & Hephaestus cable-driven robot & Conventional facade installation \\
\hline Number of workers & $\begin{array}{l}\text { - } 3 \text { workers for system setup and } \\
\text { disassembly; } 1 \text { worker for robot } \\
\text { operation }\end{array}$ & $\begin{array}{l}1 \text { for crane operation; } 5 \text { for curtain } \\
\text { wall module handling }\end{array}$ \\
\hline Speed/performance & $\begin{array}{l}\text { - } \quad \sim 15 \mathrm{~min} \text { for one bracket installation } \\
\text { - } \quad \sim 15 \mathrm{~min} \text { for one CWM installation }\end{array}$ & - $\quad \sim 30 \mathrm{~min} / \mathrm{m}^{2}$ \\
\hline Total time needed per job & $\begin{array}{l}\text { - } \quad 123 \mathrm{~h} \text { in total: } \\
\text { - } \quad 55 \mathrm{~h} \text { setup } \\
\text { - } \quad 60 \mathrm{~h} \text { curtain wall installation } \\
\text { - } \quad 8 \text { h disassembly }\end{array}$ & - $\quad 270 \mathrm{~h}$ \\
\hline
\end{tabular}

\begin{tabular}{ccc}
\hline Productivity weight coefficient & 1 & 2.20 \\
\hline Jobs finished per year & 14 & 6.36 \\
\hline $\begin{array}{l}\text { Downtime per year (e.g., holidays, } \\
\text { operational, extreme weather, etc.) }\end{array}$ & 8 weeks \\
\hline $\begin{array}{c}\text { Median wage of construction worker in } \\
\text { the UK }\end{array}$ & $3 \%$ (commonly applied in the construction sector) \\
\hline Annual wage increase & $0.1 \%$ (in the UK as of October 2020) \\
\hline Discount rate & $10 \%$ \\
\hline Annual equipment maintenance costs
\end{tabular}

Note: In addition, detailed explanations of Table 2 are listed as follows.

1. The main financial beneficiary is a curtain wall installation company operating in the UK, because the main market of facade installation for the key beneficiary is in the UK.

2. For the simplification of calculation, the table uses the median hourly rate of construction workers to calculate all the inputs related to labor costs.

3. The estimated cost of the robot system includes manufacturing cost, logistics, administrative cost, and profit.

4. The robot system does not cause extra administrative costs, compared to the conventional method.

5. A one-month training cost of $12,000 €(3000 € /$ person) is added, to train four workers for operating the robot system during the downtime of the first year. During the training month, these workers' salary needs to be covered by the company as well $(9900 €)$. After the training, one worker will become a highly-skilled operator, thus earning 30\% more salary than the average worker.

6. The annual total saving outputs equal the annual saving inputs multiplied by a productivity weight coefficient of 2.2, which means that the alternative robot system is 2.2 times as productive as the conventional method. Therefore, the productivity weight coefficient needs to be considered in the conventional method to keep up with the productivity of the alternative robot system in order to achieve the same gross revenue for fair comparison. 
7. Regarding the central cost for the company, this robot system does not require additional special managerial efforts, compared to the conventional scenario. Therefore, central costs are not calculated in both scenarios.

\section{Results}

Based on the proposed comparison scenario and collected data in the case study, the following results can be presented, including cashflow analysis, key financial indicators, sensitivity analysis, and recommendations. According to the comparison of the conventional method and cable-driven robot method for facade installation, the cashflow analysis table can be filled in detail with corresponding numbers, as below (see Figure 9).

\begin{tabular}{|c|c|c|c|c|c|c|c|}
\hline \multicolumn{8}{|c|}{ Cashflow analysis to compare novel STCR solution and conventional method } \\
\hline \multirow{2}{*}{$\begin{array}{l}\text { Key stakeholder/beneficiary } \\
\text { Cash outflows }\end{array}$} & \multicolumn{6}{|c|}{ Curtain wall installing company } & \multirow{2}{*}{\begin{tabular}{|l|l|} 
Operating region & UK \\
Explanation and remarks
\end{tabular}} \\
\hline & \begin{tabular}{|l|l|} 
Year 1 & \\
\end{tabular} & Year 2 & Year 3 & Year 4 & Year 5 & Total (€) & \\
\hline Central - hardware costs & & & & & & 0.00 & \\
\hline Central - software costs & & & & & & 0.00 & \\
\hline Central - network costs & & & & & & 0.00 & \\
\hline Central - utility costs & & & & & & 0.00 & \\
\hline Central - operation & & & & & & 0.00 & \\
\hline Central - maintenance & & & & & & 0.00 & \\
\hline Central - other & & & & & & 0.00 & \\
\hline Per robot costs - hardware & $600,000.00$ & & & & & $600,000.00$ & \\
\hline Per robot costs - software & & & & & & 0.00 & \\
\hline Per robot costs - network \& utility & $3,000.00$ & $3,000.00$ & $3,000.00$ & $3,000.00$ & $3,000.00$ & $15,000.00$ & \\
\hline Per robot costs - training & $21,900.00$ & & & & & $21,900.00$ & \\
\hline Per robot costs - transport & $5,000.00$ & $5,000.00$ & $5,000.00$ & $5,000.00$ & $5,000.00$ & $25,000.00$ & \\
\hline Per robot costs - installation & $35,735.70$ & $36,807.77$ & $37,912.00$ & $39,049.36$ & $40,220.85$ & $189,725.68$ & \\
\hline Per robot costs - operation & $16,893.24$ & $17,400.04$ & $17,922.04$ & $18,459.70$ & $19,013.49$ & $89,688.51$ & \\
\hline Per robot costs - disassembly & $5,197.92$ & $5,353.86$ & $5,514.47$ & $5,679.91$ & $5,850.30$ & $27,596.46$ & \\
\hline Per robot - maintenance & $60,000.00$ & $60,000.00$ & $60,000.00$ & $60,000.00$ & $60,000.00$ & $300,000.00$ & \\
\hline Per robot - other & & & & & & 0.00 & \\
\hline Total outflow & $747,726.86$ & $127,561.67$ & $129,348.52$ & $131,188.97$ & $133,084.64$ & $1,268,910.65$ & \\
\hline Savings - equipment & $50,000.00$ & $50,000.00$ & $50,000.00$ & $50,000.00$ & $50,000.00$ & $250,000.00$ & \\
\hline Savings - labor & $159,390.50$ & $164,172.22$ & $169,097.39$ & $174,170.31$ & $179,395.42$ & $846,225.83$ & \\
\hline Savings - utility & $1,000.00$ & $1,000.00$ & $1,000.00$ & $1,000.00$ & $1,000.00$ & $5,000.00$ & \\
\hline Savings - operational & & & & & & 0.00 & \\
\hline Savings - maintenance & $5,000.00$ & $5,000.00$ & $5,000.00$ & $5,000.00$ & $5,000.00$ & $25,000.00$ & \\
\hline Savings - other & & & & & & 0.00 & \\
\hline Total savings & $473,859.11$ & $484,378.88$ & $495,214.25$ & $506,374.68$ & $517,869.92$ & $2,477,696.83$ & \\
\hline Net annual cashflow & $-273,867.75$ & $356,817.22$ & $365,865.73$ & $375,185.70$ & $384,785.28$ & $1,208,786.18$ & \\
\hline Net cumulative cashflow & $-273,867.75$ & $82,949.47$ & $448,815.20$ & $824,000.90$ & $1,208,786.18$ & $1,208,786.18$ & \\
\hline Coefficient of productivity & & & & 20 & & & \\
\hline Annual wage increase & & & 1.0 & 03 & & & \\
\hline
\end{tabular}

Figure 9. Cashflow analysis of the proposed robot system based on the UK market.

\subsection{Key Financial Indicators of the Hephaestus Cable Robot}

As mentioned above, the key financial indicators relevant in this evaluation can be calculated based on the results of the cashflow analysis (Figure 9), including benefit-cost ratio (BCR), return on investment (ROI), payback period (PBP), initial investment value (IIV), and net present value (NPV) [4]. The key financial indicators are calculated based on the following equations:

$$
\begin{aligned}
& \mathrm{BCR}=(\mid \text { present value of benefits } \mid) /(\mid \text { present value of costs } \mid) \\
& \mathrm{ROI}=(\text { total cost savings }- \text { total outflows }) /(\mid \text { total outflows } \mid)
\end{aligned}
$$

$\mathrm{PBP}=\mathrm{n}+(\mid$ net accumulative cashflow of year $\mathrm{n} \mid) /($ net annual cashflow of year $n+1)$, $\mathrm{n}$ represents the number of the final year with negative net accumulative cashflow.

$$
\text { IIV }=(\text { initial hardware cost })+(\text { initial deployment cost })
$$

$$
\mathrm{NPV}=(\text { net annual cashflow }) /(1+\text { cost of money })^{\text {Years in the future }}
$$


As a result, the key financial indicators of the Hephaestus cable-driven robot for curtain wall installation are calculated, as below (see Table 3).

Table 3. Key financial indicators of the proposed robot system when operating in the UK.

\begin{tabular}{cc}
\hline Key Financial Indicator & Value \\
\hline Benefit-Cost Ratio (BCR) & 1.95 \\
\hline Return on Investment (ROI) & $95.26 \%$ \\
\hline Payback Period (PBP) & 21.21 months \\
\hline Initial Investment Value (IIV) & $747,726.86 €$ \\
\hline Net Present Value (NPV) & $1,205,040.19 €$ \\
\hline
\end{tabular}

Note: The definitions of the key financial indicators are listed as follows:

1. BCR indicates the overall relationship between the relative benefits and costs of a proposed project. In this case study, benefits refer to the money saved by not using the conventional facade installation method, and costs refer to the money spent to operate the robot system. If the value is larger than 1.0, the project is expected to deliver economic satisfaction to its investors.

2. ROI is a performance measure used to evaluate the efficiency of an investment.

3. $\mathrm{PBP}$ is the period of time required to recover the cost of an investment.

4. IIV is defined here as the amount of money needed for the total capital expenditures in the first year.

5. NPV is the current value of a future stream payments. Here it refers to the present value of the total net accumulative cash flow.

\subsection{Sensitivity Analysis}

Sensitivity analysis, also known as what-if analysis, is a financial tool which determines how target outputs are affected based on changes in input variables. This model is used to predict the result of a decision, given a certain set of variables. There are a wide range of uses of sensitivity analysis, which can be categorized into four main aspects: decision-making support, communication, increasing understanding of the system, and model development [24]. Based on this tool, the analyst will be able to understand which input variable is more consequential, and which one is less.

Therefore, a simple sensitivity analysis is conducted, regarding several major variables in the cashflow analysis. By adjusting each input variable $10 \%$ better and $10 \%$ worse, the total accumulative cashflow by the end of the five-year period will also change accordingly. Thus, the increase and decrease of total accumulative cashflow, compared to the original estimation, can be calculated. In this case, five main input variables, including annual wage increase, labor cost (hourly rate), robot system cost, crane renting cost, and productivity coefficient weight, are evaluated. The result is shown in Figure 10.

From the sensitivity analysis, it can be concluded that the outcome is most sensitive to the weight coefficient of productivity, followed by labor hourly rate, robot system cost, crane renting cost, and last, but not least, the annual wage increase. Other variables, such as utility cost and training cost, are not listed here due to their relative insignificance to the outcome of the analysis. The sensitivity analysis is especially important and insightful because many data acquired in this study are only rough estimations. It indicates that the most efficient way to improve profitability or benefits of the alternative system is to further improve the productivity and efficiency of the robot, although this objective might be difficult to achieve. 


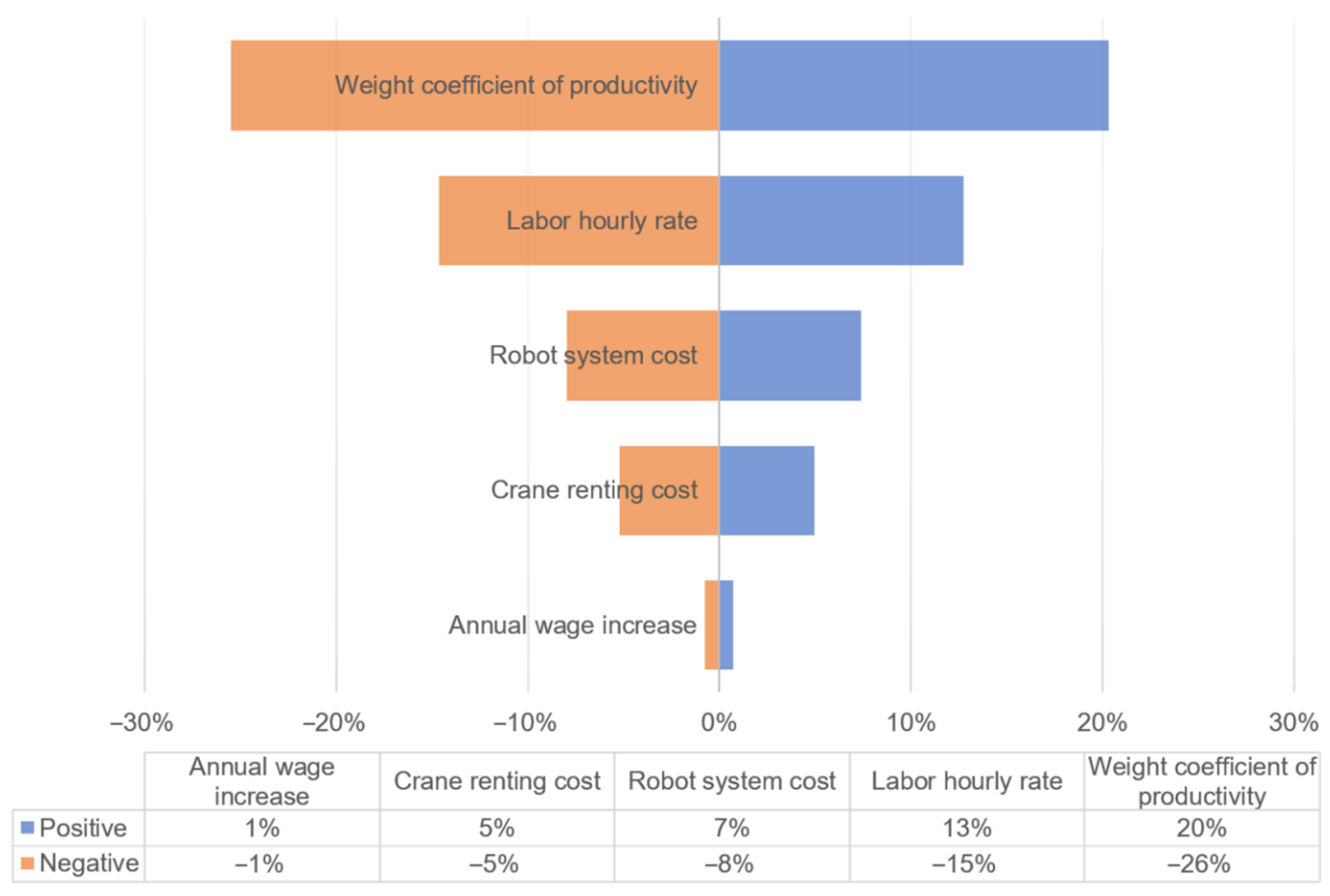

Figure 10. Sensitivity analysis of the CBA.

\subsection{Recommendations}

As mentioned in the beginning of this paper, the last part of CBA, usually, is to make a recommendation on whether the alternative option is worth considering. The results of key financial indicators indicate that the BCR is 1.95 , which exceeds 1 . Therefore, the investment of the Hephaestus cable-driven robot for CWM installation, based on the UK market, is projected to be economically acceptable and efficient. In particular, the investment of one Hephaestus cable-driven robot system could pay for itself in only 21.21 months when operated in the UK.

In accounting, the break-even point (BEP) refers to the point at which the total cost and total revenue are equal [25]. When adjusting the net cumulative cashflow to near zero in year 5, by adjusting the construction worker salary while keeping any other variables the same, it can be inferred that the investment of the Hephaestus cable-driven robot system will be worthwhile, in theory, if the local hourly wage for workers is higher than approximately $3.45 € / \mathrm{h}$. In other words, the proposed robot system for curtain wall installation task will be financially competitive in countries or regions where the median salary for a construction worker is above $3.45 € / \mathrm{h}$ as of 2020 , which is the BEP.

Furthermore, Table 4 demonstrates whether the Hephaestus cable-driven robot system is competitive in the G20 countries/regions (different currencies are converted to euros based on the exchange rates on 13 October 2020, according to Google). In this research, if the local median wage of construction workers is more than double the BEP, the investment will be defined as highly competitive; if the local median wage of construction workers is more than the BEP but less than double the BEP, it will be defined as competitive; otherwise, it will be considered as uncompetitive. Therefore, the table shows that the proposed system would currently be highly competitive, compared to the conventional method in most developed countries in the world, and it would be relatively competitive in many emerging economies as well, with a few exceptions such as Argentina, Brazil, China (mainland), India, Mexico, Russia, South Africa, and Turkey (according to www.salaryexpert.com as of October, 2020). However, as the economy continues to expand in these emerging markets and their average income of workers increases, it is predictable that the proposed system will become competitive in these countries as well in the near future. 
Table 4. Median hourly rate of construction workers in G20 countries/regions, and indications on whether the robot is competitive in the respective country.

\begin{tabular}{ccc}
\hline G20 Country or Region & Median Hourly Rate (in $€)$ & Recommendation \\
\hline Argentina & $2.19(198.68 \mathrm{ARS})$ & Uncompetitive \\
\hline Australia & $18.23(29.93 \mathrm{AUD})$ & Highly competitive \\
\hline Brazil & $3.18(21.07 \mathrm{BRL})$ & Uncompetitive \\
\hline Canada & $14.93(23.23 \mathrm{CAD})$ & Highly competitive \\
\hline China (mainland) & $3.41(27.25 \mathrm{CNY})$ & Uncompetitive \\
\hline China (Hong Kong) & $13.01(118.60 \mathrm{HKD})$ & Highly competitive \\
\hline France & 14.15 & Highly competitive \\
\hline Germany & 17.18 & Highly competitive \\
\hline India & $1.15(99.17 \mathrm{INR})$ & Uncompetitive \\
\hline Indonesia & $3.59(62053.86 \mathrm{IDR})$ & Competitive \\
\hline Italy & 13.08 & Highly competitive \\
\hline Japan & $14.66(1826.55 \mathrm{JPY})$ & Highly competitive \\
\hline Mexico & $2.41(60.66 \mathrm{MXN})$ & Uncompetitive \\
\hline Russia & $2.11(192.16 \mathrm{RUB})$ & Uncompetitive \\
\hline Saudi Arabia & $8.69(38.24 \mathrm{SAR})$ & Highly competitive \\
\hline South Africa & $3.12(60.99 \mathrm{ZAR})$ & Uncompetitive \\
\hline South Korea & $10.18(13,790.48 \mathrm{KRW})$ & Highly competitive \\
\hline Turkey & $2.51(23,41 \mathrm{TRY})$ & Uncompetitive \\
\hline United Kingdom & $15.47(14.05 \mathrm{GBP})$ & Highly competitive \\
\hline United States & $17.28(20.29 \mathrm{USD})$ & \\
\hline
\end{tabular}

The results are important indicators for companies and policy makers in different countries and regions to decide whether the investment of the Hephaestus cable-driven robot is worth considering. Furthermore, as the manufacturing costs of the robot system drop and the global labor costs increase over time, it is foreseeable that the robot system will be competitive in even more countries worldwide.

\section{Discussion}

This research introduces a simple framework for economically evaluating single-task construction robots, based on a case study of a cable-driven curtain wall installation robot. The results indicate that the CDPR system in the case study is financially competitive in the UK, as well as in most developed countries or regions. The advantages and future validation of the methods, as well as the additional socioenvironmental implications, limitations, adaptability, and reproducibility, are further discussed in the sections below.

\subsection{Advantages and Future Validation of the Methods}

This paper mainly discusses the direct economic implications of STCR, using the proposed cable-driven robot for curtain wall installation as a case study. It will be one of the first CBA research instances focusing on STCRs, setting a valuable precedent for the field of construction robots.

The methodology is practical and helpful for the key beneficiary (e.g., the construction company) to make decisions about whether to invest in construction robots without acquiring large amounts of data. The calculation method is specifically designed to estimate the costs and benefits of an advanced solution for a specific task in a short amount of time. 
Therefore, it does not require a large amount of time and effort of the key beneficiary, such as historical data collection and opinion survey.

Further, the proposed framework, as well as the results, can be further validated by the key beneficiary through a real-world pilot project in which the key performance indicators (KPIs) of the conventional and alternative scenarios (e.g., speed, performance, cost, etc.) can be more accurately measured.

\subsection{Further Socioenvironmental Implications}

The proposed methods mainly address the direct microeconomic evaluation of an STCR, compared to the traditional technique, through a simplified analyzing framework. However, more indirect socioenvironmental implications, other than productivity increase, are also worth noting. For instance, the STCR approach enhances labor safety. According to Eurostat, there were 3552 fatal accidents at work in EU-28 states during 2017, of which one fifth happened in the construction sector [26]. In other words, more than 700 accidental deaths took place within the construction industry in EU countries just in 2017. The reduction in the number of onsite construction workers at height, through applying construction robots, can substantially reduce the chance of fatal accidents and other injuries on the construction sites. Furthermore, the application of STCRs has a positive impact on construction quality through precise control and real-time monitoring, which potentially benefits the reputation and profitability of the relevant construction companies. Meanwhile, it also has a positive impact on resource consumption due to the precise automatic control system [2]. Moreover, the vacancy rate in the construction sector (excluding the real estate subsector) in the EU28 increased by 1.7\% from 2010 to 2018, indicating growing labor shortages in the business. In particular, Germany observed 121,736 unfilled positions in the construction sector in 2018, compared to only 51,892 in 2010 [27]. The implementation of robots can help alleviate the growing labor shortages in the construction business. These aspects obviously make an even stronger case in favor of construction robots, although these additional socioenvironmental benefits are more difficult to monetize.

\subsection{Limitations}

Just like any other economic models, this initial CBA is by no means an impeccable process. The results reported in this section have certain limitations, summarized as follows.

1. The usability of the alternative scenario, currently based on a prototype, needs to be further tested and validated in real-world practice.

2. Many data for calculation are only rough estimations, and more accurate data might be possible in the future.

3. The manufacturing cost of the robot is only calculated based on prototyping cost in the EU market, thus cheaper alternatives, such as outsourcing, are not considered, and future mass production might be substantially lower.

4. Many long-term indirect socioenvironmental benefits are difficult to quantify and monetize. Also, the primary beneficiary in the case study is defined as the facade installation company. Therefore, the indirect socioenvironmental benefits are not included directly in the case study.

\subsection{Adaptability and Reproducibility}

As shown in previous sections, the case study provides a simple, but useful, tool to assess the benefit and cost of any given STCR system, which fills the gap in the economic evaluation of construction robots. The demonstrated process of CBA for STCR is highly adaptable and reproducible. Therefore, researchers, engineers, investors, and policy makers can easily follow and customize this method to assess the economic advantages of any STCR system, compared to traditional construction techniques and methods. 
Author Contributions: Conceptualization, R.H., K.I., T.L., W.P. and T.B.; methodology, R.H., K.I., T.L. and C.Z.; formal analysis, R.H.; investigation, R.H., K.I. and T.B.; data curation, R.H., K.I. and A.P.; writing-original draft preparation, R.H.; writing-review and editing, R.H., T.L. and C.Z.; visualization, R.H. and K.I.; supervision, T.B. All authors have read and agreed to the published version of the manuscript.

Funding: This research was funded by the European Union's Horizon 2020 research and innovation programme under grant agreement No 732513.

Data Availability Statement: The data presented in this study are available on request from the corresponding author. The data are not publicly available due to confidentiality.

Conflicts of Interest: The authors declare no conflict of interest. The funders had no role in the design of the study; in the collection, analyses, or interpretation of data; in the writing of the manuscript; or in the decision to publish the results.

\section{References}

1. Cousineau, L.; Miura, N. Construction Robots: The search for New Building Technology in Japan; ACSE Press: Reston, VA, USA, 1998; ISBN 0784403171.

2. Bock, T.; Linner, T. Construction Robots: Elementary Technologies and Single-Task Construction Robots; Cambridge University Press: Cambridge, UK, 2016; Volume 3, p. 334.

3. Fodor, B. Estimation of Social Benefits in Cost-benefit Analysis. Theory Methodol. Pract. 2012, 8, 11-16.

4. Boardman, A.E.; Greenberg, D.H.; Vining, A.R.; Weimer, D.L. Cost-Benefit Analysis: Concepts and Practice, 5th ed.; Cambridge University Press: Cambridge, UK, 2018; ISBN 9781108415996.

5. Munger, M.C. Analyzing Policy: Choices, Conflicts, and Practices; New Institutionalism in American Politics; W. W. Norton \& Company: New York, NY, USA, 2000; ISBN 9780393973990.

6. Shen, K.; Cheng, C.; Li, X.; Zhang, Z. Environmental Cost-Benefit Analysis of Prefabricated Public Housing in Beijing. Sustainability 2019, 11, 207. [CrossRef]

7. Li, Z.; Madanu, S. Highway Project Level Life-Cycle Benefit/Cost Analysis under Certainty, Risk, and Uncertainty: Methodology with Case Study. J. Transp. Eng. 2009, 135, 516-526. [CrossRef]

8. Medici, M.; Lorenzini, G. Mathematical ILP modeling for the optimization of the energy saving in the residential buildings sector. J. Eng. Thermophys. 2014, 23, 201-215. [CrossRef]

9. Jang, W.-S.; Skibniewski, M. Cost-Benefit Analysis of Embedded Sensor System for Construction Materials Tracking. J. Constr. Eng. Manag. 2009, 135. [CrossRef]

10. García de Soto, B.; Agustí-Juan, I.; Hunhevicz, J.; Joss, S.; Graser, K.; Habert, G.; Adey, B.T. Productivity of digital fabrication in construction: Cost and time analysis of a robotically built wall. Autom. Constr. 2018, 92, 297-311. [CrossRef]

11. Kim, T.; Lee, U.; Yoo, W.S.; An, S.; Cho, H.; Lee, Y.; Doh, N. Benefit/cost analysis of a robot-based construction automation system. In Proceedings of the ICCAS 2010, Gyeonggi-do, Korea, 27-30 October 2010; pp. 616-621.

12. Wang, R.; Kudrot-E-Khuda, M.; Nakamura, F.; Tanaka, S. A Cost-benefit Analysis of Commuter Train Improvement in the Dhaka Metropolitan Area, Bangladesh. Procedia-Soc. Behav. Sci. 2014, 138, 819-829. [CrossRef]

13. Jones, H.; Moura, F.; Domingos, T. Transport Infrastructure Project Evaluation Using Cost-benefit Analysis. Procedia-Soc. Behav. Sci. 2014, 111, 400-409. [CrossRef]

14. Herzog, T.; Krippner, R.; Lang, W. Facade Construction Manual, 2nd ed.; DETAIL Business Information GmbH: Munich, Germany, 2017; ISBN 978-3955533694.

15. Taghavi, M.; Iturralde, K.; Bock, T. Cable-driven parallel robot for curtain wall modules automatic installation. In Proceedings of the 35th International Symposium on Automation and Robotics in Construction (ISARC 2018), Berlin, Germany, $20-25$ July 2018.

16. Falk, J.H.; Augustinson, D.F. Method for Mounting Facade Elements on a Multi-Storey Building. U.S. Patent 8,695,308, 15 April 2015.

17. Činkelj, J.; Kamnik, R.; Čepon, P.; Mihelj, M.; Munih, M. Closed-loop control of hydraulic telescopic handler. Autom. Constr. 2010, 19, 954-963. [CrossRef]

18. Iturralde, K.; Linner, T.; Bock, T. Development and preliminary Evaluation of a concept for a Modular End-Effector for automated/robotic Facade Panel Installation in Building Renovation. In Proceedings of the 10th Conference on Advanced Building Skins 2015, Bern, Switzerland, 3-4 November 2015.

19. Ma, J.; Iturralde, K. ECO—BOX: A system of lightweight vertical urban farming and its robotic assembly \& operation process. In Proceedings of the CIB W119 Workshop 2016, Munich, Germany, 27 October 2016; pp. 28-35.

20. Pan, W.; Bock, T.; Linner, T.; Iturralde, K. Development of a Fast and Effective Solution for On-Site Building Envelope Installation. In Proceedings of the 33rd ISARC (32nd International Symposium on Automation and Robotics in Construction), Auburn, AL, USA, 18-21 July 2016; pp. 805-811.

21. Ferravante, V.; Riva, E.; Taghavi, M.; Braghin, F.; Bock, T. Dynamic analysis of high precision construction cable-driven parallel robots. Mech. Mach. Theory 2019, 135, 54-64. [CrossRef] 
22. Gouttefarde, M.; Lamaury, J.; Reichert, C.; Bruckmann, T. A Versatile Tension Distribution Algorithm for $\mathrm{n}$-DOF Parallel Robots Driven by $\mathrm{n}+2$ Cables. IEEE Trans. Robot. 2015, 31, 1444-1457. [CrossRef]

23. Iturralde, K.; Feucht, M.; Hu, R.; Pan, W.; Schlandt, M.; Linner, T.; Bock, T.; Izard, J.-B.; Eskudero, I.; Rodriguez, M.; et al. A Cable Driven Parallel Robot with a Modular End Effector for the Installation of Curtain Wall Modules. In Proceedings of the 37th International Symposium on Automation and Robotics in Construction (ISARC), Kitakyshu, Japan, 27-28 October 2020; pp. 1472-1479.

24. Pannell, D.J. Sensitivity analysis of normative economic models: Theoretical framework and practical strategies. Agric. Econ. 1997, 16, 139-152. [CrossRef]

25. Dayananda, D.; Irons, R.; Harrison, S.; Herbohn, J.; Rowland, P. Capital Budgeting: Financial Appraisal of Investment Projects; Cambridge University Press: Cambridge, UK, 2002; ISBN 9781139434874.

26. Eurostat. Accidents at Work Statistics; Eurostat: Luxembourg, 2020.

27. European Commission. European Construction Sector Observatory-Analytical Report-Improving the Human Capital Basis-March 2020; European Commission: Brussels, Belgium, 2020. 